\title{
PENERAPAN MUSIC THERAPY BERBASIS COGNITIVE BEHAVIOR THERAPY (CBT) BAGI INDIVIDU DENGAN VISUAL IMPAIRMENT, BAGAIMANA?
}

\author{
Dominikus David Biondi Situmorang \\ Fakultas Psikologi, Universitas Indonesia \\ d.david@ui.ac.id \\ Frieda Mangunsong \\ Fakultas Psikologi, Universitas Indonesia \\ friemang@ui.ac.id
}

\begin{abstract}
Abstrak
Rancangan program ini disusun untuk membantu individu dengan visual impairment agar dapat secara optimal berfungsi dengan baik dalam menjalankan kehidupannya sehari-hari. Program terdiri dari 10 pertemuan yang dibagi menjadi dua, yaitu 5 pertemuan dalam pemberian passive music therapy berbasis cognitive behavior therapy (CBT) untuk meningkatkan self-acceptance, dan 5 pertemuan berikutnya dalam pemberian active music therapy berbasis cognitive behavior therapy (CBT) untuk mereduksi inattention.
\end{abstract}

Kata Kunci: rancangan program; difabel; penyandang disabilitas; visual impairment; low vision; music therapy; cognitive behavior therapy; self-acceptance; inattention.

\begin{abstract}
This program design is structured to help individuals with visual impairments to optimally function properly in carrying out their daily lives. The IEP consisted of 10 meetings which were divided into two, i.e. 5 meetings on the provision of cognitive behavioral therapy $(C B T)$ - based passive music therapy to improving self-acceptance, and the next 5 meetings in the provision of cognitive behavior therapy (CBT) - based active music therapy to reducing inattention.
\end{abstract}

Keywords: program design; disability; visual impairment; low vision; music therapy; cognitive behavior therapy; self-acceptance; inattention.

\section{PENDAHULUAN}

Manusia merupakan makhluk paling sempurna yang diciptakan Tuhan, namun dibalik kesempurnaan itu terdapat beberapa orang yang memiliki keterbatasan. Keterbatasan yang dimiliki individu tidak selamanya dipandang sebagai hal yang wajar, sehingga terdapat pihak yang berpandangan bahwa individu yang memiliki keterbatasan tidak sama dengan individu pada umumnya yang sempurna baik fisik maupun mentalnya (Halgin, Richard, \& Whitbourn, 2003).

Seiring dengan perkembangan zaman, anak-anak yang memiliki keterbelakangan atau kelainan, baik dalam segi fisik maupun mental telah mendapatkan perhatian dari pemerintah, terbukti dengan dikeluarkannya Undang-Undang ABK (Anak Berkebutuhan Khusus) termasuk di Indonesia, pada 
tahun 2003 diatur dalam Undang-undang Nomor 20 tentang Satuan Pendidikan Nasional Bab IV Pasal 5 Ayat 2.

Melalui undang-undang yang berlaku di Indonesia, anak berkebutuhan khusus yang memiliki keterbelakangan atau kelainan, baik dari segi fisik maupun mental dapat diwadahi melalui pelayanan pendidikan yang disesuaikan atau khusus. Seperti halnya salah satu kelainan fisik yang diderita oleh anak berkebutuhan khusus yaitu anak yang memiliki keterbatasan penglihatan/tunanetra (visual impairment).

Tunanetra (visual impairment) merupakan suatu kondisi tidak berfungsinya indera penglihatan pada seseorang secara sebagian (low vision) atau secara keseluruhan (totally blind). Hal ini dapat terjadi sebelum lahir, saat lahir dan setelah lahir. Faktor penyebab ketunanetraan pada masa sebelum kelahiran (pre-natal) sangat erat hubungannya dengan masalah keturunan dan pertumbuhan seorang anak dalam kandungan. Penyebab ketunatetraan pada masa sejak atau setelah kelahiran (post-natal), diantaranya kerusakan pada mata atau syaraf mata pada waktu persalinan akibat benturan benda keras (Hallahan \& Kauffman, 1994, 2006).

Tujuan dari dilakukannya pendidikan untuk tunanetra bukan dari kemampuan kognitif, melainkan untuk melatih kemandirian anak tunanetra (Marylin, 2005). Setiap tunanetra dituntut untuk dapat hidup mandiri. Mandiri di sini berarti ia bisa mengurus segala keperluan dirinya sendiri tanpa bantuan orang lain. Mereka harus dapat hidup mandiri supaya mereka dapat bersosialisasi dan dapat menciptakan kehidupan yang layak seperti orang normal pada umumnya. Maka dari itu, tunanetra harus mendapatkan pendidikan yang layak (Hallahan \& Kauffman, 1994, 2006).

Tujuan dari pembuatan intervensi ini adalah untuk membantu individu dengan visual impairment melalui music therapy berbasis cognitive behavior therapy (CBT). Intervensi ini dibuat untuk seorang individu yang bernama YRD, yang merupakan seorang community leader di salah satu Biro di Jakarta. Alasan pemilihan subjek ialah karena YRD memiliki permasalahan terkait low selfacceptance dan inattention. Jika dikaitkan dengan pekerjaannya sehari-hari, hal tersebut sangat mempengaruhi performanya untuk menjadi seorang good helper terhadap sesama kaum disabilitas yang ia bina.

Peneliti berharap bahwa program yang telah dibuat oleh peneliti ini tidak hanya menjadi kajian untuk pengembangan pengetahuan bagi peneliti saja, namun diharapkan dapat bermanfaat bagi YRD sendiri, keluarga, dan tempat ia bekerja. Dengan demikian, melalui intervensi yang telah disusun ini, peneliti berhadap dapat berkolaborasi dengan pihak keluarga, konselor volunteer atau peer-counselor yang ada di lembaga tempat YRD bekerja untuk dapat menerapkannya dengan baik, agar tujuan membantu YRD untuk meningkatkan self-acceptance dan attentionnya dapat tercapai. 


\section{LANDASAN TEORITIS}

\section{Pengertian Tunanetra (Visual Impairment)}

Ludíková (2012, dalam Malinovska \& Majerova, 2015) menyatakan bahwa seseorang dengan gangguan penglihatan (visual impairment) adalah setiap individu yang menderita cacat atau penyakit visual atau persepsi visual terganggu dalam tingkat yang menyebabkan masalah dalam kehidupan sehari-hari. Menurut Vágnerová (2011 dalam Malinovska \& Majerova, 2015), orang dengan gangguan penglihatan adalah individu yang tidak dapat melihat semua informasi visual dengan mudah dan tepat (visual impairment).

Seseorang dinyatakan tunanetra jika setelah dilakukan berbagai upaya perbaikan terhadap kemampuan visualnya, ternyata ketajaman visualnya tidak melebihi 20/200 atau setelah dilakukan berbagai upaya perbaikan terhadap kemampuan visualnya ternyata pandangannya tidak melebihi 20 derajat (Hallahan \& Kauffman, 1994, 2006).

Dari batasan tersebut di atas tampaknya ditekankan pada medan penglihatan (field of vision) dan ketepatan penglihatan (visual acuity). Untuk lebih jelasnya dapat dikaitkan dengan penggunaan Snellen Chart. Bila dalam Snellen Chart menunjukkan penilaian 20/20, hal ini menunjukkan bahwa seseorang dapat melihat jelas simbol yang ada pada Snellen Chart pada jarak 20 kaki demikian pula untuk ukuran mata yang normal. Dengan demikian bila dinyatakan 20/200, maka hal ini berarti orang itu hanya dapat melihat pada jarak 20 kaki sementara untuk ukuran mata/penglihatan yang normal dapat melihat pada jarak 200 kaki.

Medan penglihatan menunjukkan pada daerah yang dapat kita lihat pada satu saat tertentu, hal ini dinyatakan dalam derajat. Beberapa orang memiliki keterbatasan dalam medan penglihatannya, di mana pada situasi tertentu (misalnya pada situasi yang penuh sesak) sulit untuk bergerak secara bebas dari satu tempat ke tempat lain.

Menurut Heward (2000 dalam Mangunsong, 2009), dari kerusakan medan penglihatannya sentral atau peripheral (tepi), individu dapat dipertimbangkan sebagai buta secara legal jika ia terbatas pada medan area 20 derajat atau kurang dari normal 180 derajat. Adalah hal biasa pada medan penglihatan untuk secara perlahan-lahan menurun dalam periode tahunan dan penurunan inipun tanpa terdeteksi. Pengujian penglihatan yang menyeluruh harus meliputi pengukuran dari medan penglihatan maupun ketepatan pandangannya (p. 409).

Untuk memberikan program instruksional yang tepat bagi siswa yang mengalami hambatan/kecacatan pada penglihatannya, perlu diketahui mengenai functional vision yaitu bagaimana seseorang mempergunakan penglihatan apapun yang dimilikinya. Sehubungan dengan itu, dijelaskan bahwa gangguan penglihatan berarti adanya kerusakan penglihatan di mana walaupun sudah dilakukan perbaikan, masih mempengaruhi prestasi belajar secara optimal. 
Menurut Kauffman dan Hallahan (1994; 2006 dalam Mangunsong, 2009), berdasarkan sudut pandang pendidikan, ada dua kelompok gangguan penglihatan:

1. Siswa yang tergolong buta akademis (educationally blind), mencakup siswa yang tidak dapat lagi menggunakan penglihatannya untuk tujuan belajar huruf awas/cetak. Pendidikan yang diberikan pada siswa meliputi program pengajaran yang memberikan kesempatan anak untuk belajar melalui non-visual senses (sensori lain di luar penglihatan).

2. Siswa yang melihat sebagian atau kurang awas (the partially sighted/low vision), meliputi siswa dengan penglihatan yang masih berfungsi secara cukup, di antara 20/70-20/200, atau mereka yang mempunyai ketajaman penglihatan normal tapi medan pandangan kurang dari 20 derajat. Dengan demikian cara belajar utamanya dapat semaksimal mungkin menggunakan sisa penglihatan (visualnya).

Siswa yang kurang awas memiliki kesulitan dalam mengerjakan tugas-tugas yang berupa tugas visual. Akan tetapi jika dibantu dengan beberapa lensa, mereka masih bisa meningkatkan kemampuannya dalam menyelesaikan tugas dengan menggunakan strategi penglihatan lain, seperti peralatan untuk low vision, dan modifikasi lingkungan.

\section{Karakteristik Tunanetra (Visual Impairment)}

Ciri utama dari mereka yang mengalami gangguan penglihatan/tunanetra adalah adanya penglihatan yang tidak normal. Bentuk-bentuk ketidaknormalannya dapat dilihat dari:

\section{Perkembangan Secara Umum/Fisik}

1. Penglihatan samar-samar untuk jarak dekat atau jauh. Hal ini dijumpai pada kasus myopia, hyperopia, ataupun astigmatismus. Semua ini masih dapat diatasi dengan menggunakan kacamata ataupun lensa kontak.

2. Medan penglihatan yang terbatas, misalnya hanya jelas melihat tepi/perifer atau sentral. Dapat terjadi pada salah satu atau kedua bola mata.

3. Tidak mampu membedakan warna.

4. Adaptasi terhadap terang dan gelap terhambat. Banyak terjadi pada proses penuaan.

5. Sangat sensitif/peka terhadap cahaya atau ruang terang atau photopobic. Orang-orang albino biasanya merasa kurang nyaman berada dalam ruangan yang terang.

Kelima ciri tersebut dapat mempengaruhi perkembangan dalam berbagai bidang.

\section{Etiologi/Penyebab}

Ada berbagai penyebab dan jenis kerusakan penglihatan yang bisa terjadi sejak masa prenatal, sebelum anak dilahirkan, pada proses kelahiran maupun pasca lahir. Kerusakan atau kehilangan 
penglihatan jarang terjadi pada usia belasan; kalaupun terjadi biasanya karena luka terbentur benda keras, bola, kecelakaan kendaraan, dan lain-lain.

Kerusakan penglihatan sejak lahir disebut congenital blindness, yang dapat disebabkan oleh bermacam penyebab, seperti keturunan, infeksi (misalnya campak Jerman), yang bisa juga ditularkan oleh ibu saat janin masih dalam proses pembentukan di saat kehamilan. Kondisi yang dapat menyebabkan gangguan penglihatan termasuk (Hallahan \& Kauffman, 2006; Pierangelo, 2003 dalam Mangunsong, 2009):

1. Myopia (penglihatan dekat), terjadi sinar dari objek yang jauh tidak fokus pada retina. Kondisi ini menyebabkan individu hanya dapat melihat objek lebih jelas dari jarak dekat (close up).

2. Hyperopia (penglihatan jauh), terjadi karena mata terlalu pendek dan cahaya dari objek dekat tidak fokus pada retina. Kondisi ini menyebabkan individu dapat melihat objek lebih jelas dari jarak jauh.

3. Astigmatism (penglihatan kabur), disebabkan karena tidak imbangnya lengkungan kornea atau lensa mata. Lengkungan ini mencegah sinar cahaya terfokus dengan tepat pada retina. Kondisi ini biasanya dapat dikoreksi dengan perbaikan lensa atau lensa kontak.

4. Cataracts, kekaburan pada lensa mata karena adanya selaput sehingga penglihatan terganggu, berawan, ganda atau tidak lengkap.

5. Glaucoma, kondisi yang disebabkan kegagalan dari keenceran cairan bersirkulasi. Hal ini mengakibatkan elevasi tekanan pada mata, yang secara bertahap akan merusak syaraf optik.

6. Diabetic retinopathy, ditemukan pada anak-anak dan orang dewasa penderita diabetes (kencing manis). Kerusakan mata terjadi karena pendarahan dan pertumbuhan pembuluh darah baru di daerah retina. Dapat ditolong dengan bedah laser.

7. Retinitis pigmentosa, terjadi pada anak-anak karena penyakit yang diturunkan, menyebabkan kemunduran bertahap pada retina. Kondisi ini tidak dapat diperbaiki.

8. Cortical visual impairment, terutama dihasilkan oleh adanya kerusakan atau disfungsi otak.

9. Usher's syndrome, hasil dari kombinasi ketulian kongenital dan retinitis pigmentosa.

10. Macular degeneration, kerusakan gradual dan progresif pada macula, bagian yang sensitif pada retina. Kondisi yang biasa terjadi di mana area pusat penglihatan semakin memburuk kondisinya. Individu biasanya mempertahankan penglihatan tepi, tetapi kehilangan kemampuan melihat jelas lapangan penglihatan bagian tengahnya. Gejalanya seperti 
kesulitan membaca atau menonton $\mathrm{TV}$, atau penglihatan yang terdistorsi di mana garis lurus terlihat bergelombang atau objek terlihat lebih besar atau lebih kecil dari biasanya.

11. Retrolental fibroplasia, merupakan kondisi akibat penggunaan oksigen yang berlebihan ketika bayi prematur di dalam inkubasi.

12. Retinopathy of prematurity, disebabkan oleh konsentrasi oksigen yang berlebihan atau faktor lain.

13. Amblyopia, adalah pengurangan penglihatan pada sebuah mata karena kurang digunakan saat usia dini.

14. Strabismus (mata juling), fungsi otot yang tidak sempurna dan menimbulkan masalah penglihatan.

15. Nystagmus, kondisi di mana ada gerakan-gerakan cepat pada mata yang tidak disadari.

16. Trachoma, muncul saat tertular mikro organisma yang disebut chlamydia trachomatis disebabkan peradangan pada mata. Seringkali ditemukan di pedesaan miskin dengan kondisi yang kumuh, sesak, kurang air dan sanitasi yang memadai.

17. Neurogical visual impairment, bagian dari otak yang menyebabkan kerusakan penglihatan. Artinya, mata itu sendiri normal tetapi otak tidak dapat memproses informasi dengan baik.

18. Problem lain seperti: diasosiasikan dengan Albinism, komplikasi dari virus Rubella, kurangnya vitamin A (xerophthalmia), kelahiran dengan berat badan rendah, dan defisiensi warna.

Penting juga bagi pendidik untuk mengetahui usia terjadinya kebutaan pada individu. Anak yang buta sejak lahir secara alamiah memiliki persepsi tentang dunia yang jelas berbeda daripada anak yang kehilangan penglihatannya pada usia 12 tahun. Anak yang pertama akan memiliki latarbelakang proses belajar melalui pendengaran, perabaan, dan indra non-visual lainnya. Tentunya berbeda dengan anak yang kedua, yang memiliki latarbelakang pengalaman visual yang dapat digambarkannya secara luas. Memori ingatan visual akan dapat membantu dalam pendidikan anak seperti gambaran tentang warna, peta, dan huruf cetak. Pada saat yang sama, bagaimanapun, kebutuhan akan dukungan emosional dan penerimaannya akan lebih besar daripada anak yang buta sejak lahir, yang tidak perlu melakukan penyesuaian mendadak karena penglihatannya yang hilang (Heward, 2000, p. 409-410 dalam Mangunsong, 2009). 


\section{PEMBAHASAN}

\section{Profil Subjek}

Pada saat bayi, YRD merupakan bayi prematur (lahir pada usia kehamilan 7 bulan). Sebagai bayi prematur, YRD dirawat di dalam inkubator. Pada usia 1 minggu, dokter telah mendiagnosa bahwa YRD memiliki kelemahan di penglihatannya. Hal ini ditandai dengan adanya katarak pada matanya dan ia tidak memberikan respon "takut" terhadap cahaya matahari. Pada saat itu, orangtuanya tidak berani untuk melakukan operasi, karena dianggap YRD masih terlalu kecil untuk menjalankan operasi.

Terkait dengan perkembangan status low-vision yang dimiliki, YRD sudah memiliki indikasi akan mengalami visual impairment sejak bayi. Penglihatan yang dimiliki oleh YRD masih cukup baik sampai dengan di kelas 2 SD, kemudian mengalami penurunan ketika kelas 3 SD. YRD mengaku bahwa di kelas 3 SD tersebut, karena kualitas penglihatannya yang semakin menurun, ia kerapkali mendapatkan perundungan dari teman-teman kelasnya dengan sebutan "si mata picek" (dalam Bahasa Indonesia artinya buta). Ia pun kerapkali ketika sedang berjalan, kakinya disandung secara sengaja oleh teman-temannya. Hal inilah yang membuatnya tidak bersemangat untuk bersekolah, sehingga mengakibatkan dirinya tidak naik kelas saat itu, dan harus berpindah sekolah.

Selanjutnya, di bangku SMP, YRD mengaku bahwa dirinya masih bisa berlari dan dapat membawa kendaraan bermotor, walaupun dengan kecepatan yang masih bisa dikontrol. Kemudian, barulah pada tahun 2007 (di kelas 2 SMA), YRD mengalami infeksi mata yang kemudian timbul penyakit retina ablasio (putusnya syaraf penyanggah retina mata). YRD mengaku bahwa pada awalnya, disebabkan oleh matanya yang mengalami kekeringan, akibat 7 hari 7 malam menangis tanpa henti, berkat meninggalnya nenek dan mantan kekasihnya. Suatu ketika ia membolos, dengan alasan hendak ke tempat peristirahatan terakhir nenek dan mantan kekasihnya tersebut. Kemudian, ayahnya marah besar karena melihat perilakunya yang membolos, dan akumulasi dari kemarahan sebelumnya yang melihat perilaku YRD yang cukup “aneh" ketika berada di dalam rumah, yaitu ia cenderung tantrum dan agresif. Dalam meluapkan kemarahannya tersebut, ayahnya memukul YRD, yang tanpa disengaja terkena matanya. Setelah 3 minggu, akhirnya YRD semakin mengalami kerusakan pada penglihatannya. Ia mengaku bahwa ketika melihat garis lurus, berubah menjadi bengkok-bengkok, kemudian objek yang ia lihat berubah menjadi memiliki dua bayangan, dan matanya kurang tanggap dengan cahaya. Setelah diperiksakan ke dokter, akhirnya mendapat diagnosa bahwa YRD akan mengalami totally blind (progresif) dari waktu ke waktu. 


\section{Kondisi Internal}

\section{Perilaku, Emosi, dan Sosial}

Dalam hal perilaku dan emosi, YRD menunjukkan perilaku dan emosi yang cukup adaptif. Hal ini ditandai dengan perilaku dan emosi yang ditampakkan tidak mengindikasikan adanya keanehan. Kemudian, dalam hal sosial, YRD merupakan sosok yang dikenal friendly dan menyenangkan. Hal inilah yang membuatnya dipercaya untuk menjadi community leader di lembaga ia bekerja.

\section{Intelektual}

YRD memiliki skor tes IQ pada saat SD sebesar 95, kemudian pada saat SMA sebesar 102. YRD juga memiliki skor TOEFL yang cukup baik yaitu sebesar 490. Secara intelektual, YRD menunjukkan kecerdasan yang cukup, namun ia mengaku bahwa selama ini ia memiliki hambatan dalam proses belajarnya. Dalam mengakses sumber bacaan (PDF) yang bebas hak cipta, agar bisa terbaca dengan Jaws, ia cukup sulit menemukan. Ia mengaku bahwa banyak buku sumber yang terprotect sehingga sulit untuk dibaca oleh Jaws. Selain itu juga, ia membutuhkan asisten untuk membacakan bacaan yang tidak mampu terbaca oleh Jaws tersebut, namun ia tidak memiliki asisten yang tetap untuk membantunya selalu. Selanjutnya, YRD mengaku bahwa para dosen di Universitas yang dulu sempat ia berkuliah, mengeluhkan bahwa ia tidak dapat mengumpulkan tugas tepat pada waktunya (karena pada dasarnya, ia membutuhkan waktu yang lebih lama dibandingkan dengan orang-orang normal lainnya).

\section{Kemampuan Mobilitas dan Aksesibilitas Assistive Technology (AT)}

Sebagai seseorang dengan low vision, YRD memiliki kemampuan mobilitas yang cukup baik. Ia mampu berjalan sendiri tanpa menggunakan tongkat dan tanpa dituntun oleh orang lain. Selain itu juga, ia sangat mahir dalam penggunaan aksesibilitas AT (Assistive Technology). Hal ini ditandai dengan beberapa fitur yang terdapat di HP pribadinya, untuk membantunya dalam kehidupan seharihari.

\section{Kelemahan}

Sebagai seorang community leader, YRD mengaku bahwa kelemahan atau permasalahan yang tengah ia alami ialah terkait sulitnya untuk dapat fokus (pay attention) pada saat mendengarkan orang lain yang melakukan konseling dengan dirinya. Ia cenderung untuk langsung berfokus pada solusi, padahal hal ini sangat kurang tepat. Selain itu juga, ia mengaku bahwa ia sulit untuk fokus (pay attention) pada pilihan aktivitas yang sedang ia kerjakan. Misalnya, pada saat bekerja, kemudian ia mendapatkan informasi terkait adanya sebuah seminar yang menarik bagi dirinya, maka ia memutuskan untuk bolos bekerja dan mengikuti seminar tersebut. Contoh lainnya, ketika sedang mengerjakan sesuatu yang penting, ia mendengar bahwa ada kegiatan lain di luar pekerjaanya, maka 
ia cenderung untuk mengikuti kegiatan tersebut. Ia mengaku bahwa kesempatan tidak akan pernah datang dua kali, sehingga ia selalu cenderung inattention terhadap pekerjaan yang sedang ia kerjakan. Akhirnya, hampir setiap pekerjaannya terbengkalai.

\section{Kekuatan}

YRD memiliki kemampuan musik yang cukup mumpuni, khususnya di alat musik keyboard. Di tempat ia bekerja, ia dipercayakan untuk menjadi keyboardist untuk paduan suara Laetitia (para penyandang tuna netra). Selain itu juga, YRD memiliki kemampuan sosialisasi yang baik (friendly), dan ia sangat menyukai hal baru.

\section{Permasalahan yang dikeluhkan}

\section{Masalah Psikologis (Self-Acceptance)}

Terkadang ia belum bisa memaafkan ayahnya, karena memukulnya pada saat SMA. Hal ini yang menyebabkan semakin menurunnya penglihatan yang ia miliki; dan sampai saat ini, ia belum bisa menerima keadaan bahwa ia harus mengalami kebutaan yang progresif.

2. Masalah Belajar dan Perhatian (Attention)

Ia tidak memiliki fokus yang baik, pikirannya selalu bercabang (inattention); dan ia khawatir mengalami kegagalan kembali pada saat nanti berkuliah lagi, karena perhatiannya yang mudah teralihkan.

\section{Kondisi Eksternal}

\section{Latar Belakang dan Kondisi dalam Keluarga}

Sejak 2010 mengenal sosok YRD, akhirnya peneliti mendapatkan informasi yang cukup mengagetkan bahwa sebenarnya ia merupakan seorang anak yang diadopsi dari panti asuhan. YRD mengaku bahwa mengetahui hal tersebut ketika ibunya sakit parah dan terbaring di rumah sakit. Sebelum ibunya meninggal dunia, ibunya berjanji untuk menceritakan hal itu semua kepada YRD. Saat itu, YRD cukup merasa kaget dan sangat ingin mencari orangtua kandungnya.

YRD mengaku bahwa ia hanya memiliki interaksi relasi yang cukup baik dengan ibunya. YRD memiliki konflik internal dengan ayahnya, yang sampai saat ini masih menjadi luka bagi dirinya. Ia tidak akan pernah melupakan perbuatan yang telah ayahnya lakukan terhadap dirinya, yaitu memukul dirinya hingga penglihatannya mengalami penurunan. Saat ini, ayahnya telah pindah ke Malang, sedangkan YRD tetap berada di Jakarta, tinggal bersama budenya.

Sebagai anak kedua di keluarga, ia pun tidak pernah mendapatkan kasih sayang dari kakaknya. Sejak kecil, ia sudah terpisah jauh dari kakaknya tersebut. Ia di Jakarta, sedangkan kakaknya berada di Bali menjadi seorang polisi. Hubungan dengan kakaknya tersebut, ia mengaku bahwa tidak ada komunikasi sampai saat ini. 


\section{Tetangga dan Lingkungan Keseharian}

YRD mengaku bahwa dirinya cenderung tertutup terhadap tetangga dan lingkungan sekitar rumahnya. Ia pernah merasakan kekecewaan, bahwa pada saat ibunya sakit keras, tetangga sekitar rumahnya tidak ada yang mau membantu untuk membawa ke rumah sakit. Hal inilah yang membuat dirinya sampai saat ini tertutup terhadap tetangga sekitar.

\section{Rekan Kerja}

Di tempat YRD bekerja, ia tampak menjadi orang yang sangat berbeda seperti pada saat ketika berada di rumah. Di rumah, YRD cenderung bersikap tertutup, sedangkan ketika berada di tempat kerja, YRD menjadi pribadi yang cukup riang dan menyenangkan. Hal ini ditandai dengan banyaknya rekan kerja yang berinteraksi dengan dirinya, selain itu juga berkat pribadinya yang cukup menyenangkan tersebut, YRD mendapatkan kepercayaan untuk menjadi community leader di tempat ia bekerja.

\section{Program Intervensi}

\section{Rasional}

Berdasarkan identifikasi kasus di atas, dapat diketahui bahwa YRD mengalami kesulitan untuk fokus pada saat mengerjakan sesuatu (inattention). Hal ini menyebabkan YRD terkadang sulit menyelesaikan apapun yang ia kerjakan secara tuntas. Selain itu juga, YRD masih memiliki unfinished business terhadap pengalaman masa lalunya terhadap figur seorang ayah, sehingga ia pun harus memiliki self-acceptance yang cukup agar dapat menerima kondisi dirinya dan memaafkan ayahnya.

Selanjutnya, peneliti memutuskan untuk membuat program pembentukan perilaku mengatasi inattention dan meningkatkan self-acceptance melalui music therapy berbasis cognitive behavior therapy (CBT). Program ini merupakan program yang cukup sederhana, karena YRD sebagai individu dengan visual impairment sangat menyukai musik, sehingga dalam penerapannya akan dapat membuat YRD tertarik. Selain itu juga, program yang disusun ini nantinya akan mudah dilakukan oleh para konselor volunteer atau peer-counselor di tempat ia bekerja maupun significant others di rumah.

\section{Pandangan Cognitive Behavior Therapy (CBT) terhadap suatu Masalah}

Cognitive Behavior Therapy (CBT) memiliki pandangan yang khas dalam melihat sebuah masalah yang dialami oleh seorang individu. Setiap masalah yang ada merupakan negative thought dan cognitive distortion yang bersumber dari core belief yang maladaptif (Corey, 2013). Oleh sebab itu, konseling CBT berfokus pada proses mengubah negative thought dan cognitive distortion menjadi 
lebih adaptif kembali, dengan tujuan agar individu tersebut memiliki core belief yang lebih adaptif sehingga perasaan dan perilaku individu tersebut dapat menjadi lebih baik lagi dari sebelumnya.

Jika dikaitkan dengan permahasalahan yang dialami oleh YRD, CBT memiliki pandangan bahwa hal tersebut merupakan sebuah cognitive distortion yang bersumber dari core belief yang maladaptif. Lebih lanjut, Corey (2013) menjelaskan mengenai hierarki pikiran yang mengakibatkan individu mengalami masalah. Hierarki pikiran tersebut dibagi menjadi tiga bagian utama yaitu negative automatic thoughts (NATs), basic assumption, dan core belief. NATs merupakan pikiranpikiran negatif yang muncul secara otomatis, cepat, dan tanpa sadar. Kemudian, basic assumption merupakan suatu asumsi yang mendasari individu dalam menetapkan standar, nilai-nilai, dan aturan untuk hidup. Sementara, core belief merupakan keyakinan paling dasar mengenai diri sendiri yang terbentuk dari pengalaman-pengalaman masa lalu. Dalam hal ini, YRD memiliki keyakinan bahwa ia tidak berdaya. Core belief inilah yang dapat memunculkan cognitive distortion, yaitu kondisi yang menggambarkan pikiran depresif tentang self-acceptance yang rendah, sehingga YRD mengalami masalah dan memiliki persepsi tertentu dari masalahnya tersebut.

Cognitive distortion yang dialami oleh YRD tersebut juga akan mengakibatkan gangguan terhadap reaksi tubuh, perasaan, dan perilaku (Corey, 2013). Reaksi tubuh yang muncul bisa seperti jantung berdebar, insomnia, keringat dingin, gemetar, dan lain sebagainya. Kemudian perasaan yang muncul ialah YRD mengalami ketidakpuasan terhadap hidupnya, merasa memiliki harga diri yang rendah, tidak percaya diri terhadap kemampuan pribadi, merasa cemas dan takut gagal, serta cemas tidak dapat lulus lagi jika ia mendapatkan kesempatan untuk berkuliah lagi. Selanjutnya, perilaku yang muncul ialah YRD cenderung tidak fokus dalam melakukan pekerjaannya (inattention), dan cenderung memikirkan hal lain di luar apa yang ia kerjakan.

\section{Musik untuk Inattention dan Self-Acceptance}

Secara psikologis, musik memiliki hubungan yang positif dalam kehidupan manusia (Wigram et al., 2002). Musik dapat membuat tubuh menjadi lebih rileks, mengurangi stres, menimbulkan rasa aman, meningkatkan kesejahteraan, meningkatkan rasa bahagia, meningkatkan konsentrasi atau daya fokus (attention), membantu kesadaran diri, penerimaan diri (self-acceptance), dan membantu melepaskan rasa sakit (Djohan, 2006). Menurut Vianna, Barbosa, Carvalhaes, dan Cunha (2011), hal tersebut dikarenakan musik dapat meningkatkan produksi empat hormon positif dalam tubuh yaitu endorphin, dopamin, serotonin, dan oksitosin. Keempat hormon inilah yang berfungsi membuat tubuh menjadi lebih positif. Hal ini diperkuat juga oleh penelitian yang dilakukan oleh Laura, Sylvie, dan Aurore (2015), dan Zarate (2016) yang telah membuktikan bahwa musik dapat meningkatkan produksi hormon endorphin dan serotonin. Hasil penelitian tersebut menunjukkan bahwa dengan 
musik, seorang individu dapat merasa lebih bahagia, konsentrasi atau daya fokus (attention) dan penerimaan diri (self-acceptance).

\section{Musik dalam Konseling sebagai Music Therapy}

Penggunaan musik dalam proses konseling dikenal dengan istilah music therapy. Capuzzi \& Gross (2011) dan Sharf (2012), mengkaji lebih lanjut mengenai music therapy sebagai salah satu bentuk intervensi terapi ekspresif/seni kreatif dalam integrative approach, yang dapat diintegrasikan dengan pendekatan konseling konvensional. Dalam jurnal yang dituliskan oleh Bastemur, DursunBilgin, Yildiz, dan Ucar (2016) dipaparkan bahwa music therapy merupakan salah satu teknik alternatif yang dapat dilakukan oleh konselor dalam membantu konseli mengentaskan permasalahannya. Namun kenyataannya di lapangan, secara khusus di Indonesia, para konselor masih belum terbiasa menerapkan bentuk intervensi music therapy ini di dalam layanan konseling seharihari. Hal ini dibuktikan dengan sedikitnya jumlah kajian literatur buku konseling Indonesia yang membahas mengenai music therapy, juga sedikitnya penelitian mengenai music therapy yang diterapkan dalam praktik konseling, dan sedikitnya pembahasan mengenai music therapy dalam kehidupan sehari-hari di Indonesia (Djohan, 2006).

Skudrzyk et al. (2014) dan Gladding (2016) mengatakan bahwa pada dasarnya melalui aktivitas mendengarkan dan memainkan musik secara aktif, dapat membantu individu memahami perkembangan emosi dan kognitif mereka secara lebih sadar. Dengan penggunaan musik dalam praktik konseling, konselor juga dapat membuat proses konseling yang biasa bisa menjadi lebih menarik dan efektif. Hal ini didukung juga oleh Bradley, Whiting, Hendricks, Parr, dan Jones Jr. (2014) yang mengatakan bahwa melalui musik, konselor dan konseli dapat melakukan reframing ide, memfokuskan perspektif, melakukan eksternalisasi emosi, dan memperdalam pemahaman diri berdasarkan pengalaman atau masalah yang tengah dialami.

\section{Konseling CBT dengan Music Therapy}

Berdasarkan kajian yang dilakukan oleh Wigram et al. (2002), beberapa pendekatan konseling konvensional dapat diintegrasikan dengan music therapy. Namun, secara lebih spesifik setiap pendekatan memiliki kekhasan khusus dalam memandang suatu masalah. Hal ini yang harus disesuaikan dengan kebutuhan dan tujuan dari konseling itu sendiri. Jika dikaitkan dengan permasalahan inattention dan low self-acceptance yang merupakan sebuah cognitive distortion yang dialami oleh YRD, maka pendekatan konvensional yang tepat untuk mengentaskan permasalahan ini ialah CBT.

Beberapa penelitian mutakhir dunia mengenai music therapy yang berpedoman pada teori CBT dalam pelaksanaan konseling cukup banyak dilakukan, yaitu di antaranya penelitian yang dilakukan oleh Baker, Gleadhill, dan Dingle (2007), Flowers dan Wang (2002); Fredenburg dan 
Silverman (2014), Giovagnoli, Oliveri, Schifano, dan Raglio (2014), Gómez Gallego dan Gómez Garcia (2017), Gomez-Romero et al. (2016), Gourgey (1998), Hui-Chi Li et al. (2015), Robb (2003), Rogers et al. (2007), Spahn, (2015), Vargas (2015).

\section{Music Therapy sebagai Teknik CBT}

Corey (2012) mengatakan bahwa dalam penerapan konseling CBT, keputusan yang diambil oleh konselor untuk menggunakan teknik-teknik tertentu harus berdasarkan tujuan dan keefektifan yang dimiliki. Dalam praktik konseling CBT, pemilihan teknik cukup luas, dan banyak di antara para konselor CBT sangat eklektik (integratif) dalam menerapkan teknik pada porses konseling yang dilakukan. Mereka lebih fleksibel dalam menggunakan beberapa teknik dari banyak pendekatan konseling untuk membantu konselinya mengentaskan permasalahan yang dihadapi, khususnya untuk mengubah pola berpikir, perasaan, dan perilaku yang dimiliki oleh konseli mereka.

Salah satu teknik dalam pelaksaan konseling eklektik (integratif) CBT ialah dengan music therapy (Capuzzi \& Gross, 2011; Sharf, 2012; White \& Davis, 2011). Dalam penerapannya, music therapy itu di bagi menjadi dua, yaitu passive music therapy dan active music therapy (Gladding, 2016; Wigram et al., 2002). Passive music therapy adalah proses pemberian music therapy yang dilakukan oleh konselor, dengan cara mengajak konseli untuk mendengarkan musik atau lagu tertentu secara seksama dalam suasana yang terapeutik. Sementara, active music therapy adalah proses pemberian music therapy yang dilakukan oleh konselor, dengan cara mengajak konseli untuk memainkan alat musik, bernyanyi, maupun menciptakan lagu. Kedua teknik music therapy tersebut dapat dilaksanakan di dalam praktik konseling individual maupun kelompok (Wigram et al., 2002).

Passive vs Active Music Therapy dalam Konseling CBT bagi Individu dengan Visual

\section{Impairment}

Dalam penanganan kasus YRD ini, pemberian konseling CBT dengan teknik passive music therapy akan berfokus pada penyelesaian masalah low self-acceptance yang dialami, sementara dengan teknik active music therapy akan berfokus pada penyelesaian masalah inattention.

Corey (2013) mengatakan bahwa dalam penerapan konseling CBT, keputusan yang diambil oleh konselor untuk menggunakan teknik-teknik tertentu harus berdasarkan tujuan dan keefektifan yang dimiliki. Dalam praktik konseling CBT, pemilihan teknik cukup luas, dan banyak di antara para konselor CBT sangat eklektik (integratif) dalam menerapkan teknik pada porses konseling yang dilakukan. Mereka lebih fleksibel dalam menggunakan beberapa teknik dari banyak pendekatan konseling untuk membantu konselinya mengentaskan permasalahan yang dihadapi, khususnya untuk mengubah pola berpikir, perasaan, dan perilaku yang dimiliki oleh konseli mereka.

Passive music therapy merupakan salah satu teknik music therapy yang dapat dipergunakan dalam proses konseling (Gladding, 2016; Wigram et al., 2002). Passive music therapy adalah sebuah 
teknik dalam terapi, konseling, dan pembinaan untuk membantu individu atau sekelompok orang agar menjadi sadar dan dapat mengatasi masalah dalam kehidupan nyata, dengan bantuan melalui mendengarkan musik secara reseptif dengan guided imagery. Passive music therapy dilakukan dengan merefleksi dan berdiskusi tentang pengalaman masa lalu, pengalaman masa kini, dan harapanharapan di masa depan.

Jika dipandang dari pendekatan CBT, memanfaatkan musik sebagai sebuah sarana bantuan dapat menyediakan perangkat yang mendukung untuk memahami keyakinan inti maladaptif dan restrukturisasi kognitif individu. Selain itu, musik dapat merubah perasaan, memberikan pemahaman baru dan meningkatkan kemungkinan bahwa individu akan melaksanakan perilaku baru dan diinginkan. Melalui passive music therapy dengan guided imagery, seseorang dapat belajar bagaimana perilaku yang maladaptif diubah menjadi perilaku yang lebih adaptif (Wigram et al., 2002).

Passive music therapy sangat memengaruhi individu karena dampak sinergis dari musik, dialog, dan efek suara. Dengan passive music therapy membawa konseli ke dalam setiap peristiwa penting dalam kehidupannya (Wigram et al., 2002). Berdasarkan pandangan psikoanalisis, memanfaatkan passive music therapy dalam terapi dapat membuat alam bawah sadar berkomunikasi dengan pikiran sadar dari musik yang didengarkan (Wigram et al., 2002). Saat musik diperdengarkan, perasaan individu akan tersentuh oleh alunan musik dan guided imagery dengan emosi menyenangkan atau tidak menyenangkan yang mencerminkan pengalaman individu secara simbolis menuju alam sadar.

Passive music therapy dengan guided imagery adalah intervensi terapeutik yang memungkinkan konseli menilai secara visual di dalam imajinasinya mengenai pengalamanpengalaman berinteraksi dengan orang lain, lingkungannya, dan masalah-masalah pribadi. Dengan passive music therapy dengan guided imagery dapat membantu memperkuat aliansi terapeutik dengan komunikasi dan pengalaman antara konseli dengan konselor (Wigram et al., 2002). Bahkan, penggunaan passive music therapy dalam konseling memungkinkan konselor untuk dapat menarik kesimpulan dari beberapa orientasi psikologis (Gladding, 2016).

Dari penjelasan di atas, dapat dianalisis bahwa passive music therapy adalah salah satu teknik yang dapat digunakan dalam proses konseling dengan menggunakan musik dengan guided imagery guna menumbuhkan eksplorasi diri dan pengubahan guna mengatasi masalah individu. Jika dikaitkan dengan CBT dalam memandang dan low self-acceptance yang dialami oleh YRD, selanjutnya dapat disimpulkan bahwa konseling kelompok CBT dengan teknik passive music therapy adalah layanan yang diberikan untuk membantu YRD menyadari secara penuh mengenai low self-acceptance, kemudian mengevaluasi perasaannya tersebut berdasarkan pengalaman masa lalunya yang tidak 
menyenangkan. Selanjutnya, YRD diajak untuk berdamai dengan pengalaman masa lalunya tersebut, dan mengoptimalkan kemampuan yang dimiliki agar dapat memiliki high self-acceptance melalui aktivitas mendengarkan musik secara reseptif/pasif dengan guided imagery.

Lebih lanjut, active music therapy merupakan salah satu teknik music therapy yang dapat dipergunakan dalam proses konseling juga (Gladding, 2016; Wigram et al., 2002). Active music therapy adalah sebuah teknik dalam terapi, konseling, dan pembinaan untuk membantu individu atau sekelompok orang agar menjadi sadar dan dapat mengatasi masalah dalam kehidupan nyata, dengan bantuan melalui memainkan musik secara aktif, meliputi menciptakan lagu (composing), improvisasi, dan re-creating music. Active music therapy dilakukan dengan upaya berdiskusi tentang pengalaman masa lalu, pengalaman masa kini, dan harapan-harapan di masa depan melalui menciptakan lagu baru yang dibimbing oleh pemimpin konseling, melakukan improvisasi dengan lagu tertentu, dan memainkan alat musik secara bersama-sama dengan lagu yang sudah dikenal.

Melalui active music therapy dengan menciptakan lagu (composing), improvisasi, dan recreating music, individu dapat belajar bagaimana dapat mengubah kebiasaan lama yang maladaptif menjadi lebih adaptif. Active music therapy merupakan teknik yang memanfaatkan peralatan musik yang dimainkan secara bersama-sama (Wigram et al., 2002). Memainkan musik secara bersama-sama dapat memengaruhi sikap, perasaan, dan perilaku individu. Active music therapy melibatkan jenis instrumen yang dimainkan, lagu atau musik yang dipilih, dan lirik yang diciptakan, yang semuanya memiliki tujuan terapeutik.

Dalam layanan konseling, active music therapy menawarkan konselor mengenai strategi yang kreatif dan menyenangkan. Konselor dapat menggunakan active music therapy sebagai intervensi untuk memfasilitasi konseli dalam memperoleh keakraban, mengidentifikasi keunikan pribadi, dan perasaan konseli (Gladding, 2016). Active music therapy juga dapat digunakan sebagai mekanisme terapi untuk membantu membangun hubungan konseling, mengeksplorasi isu-isu gaya hidup, untuk mempromosikan wawasan dan kesadaran, dan reorientasi (Wigram et al., 2002).

Berdasarkan penjelasan di atas, dapat disimpulkan bahwa active music therapy adalah salah satu teknik yang dapat digunakan dalam proses konseling dengan memainkan musik secara aktif, meliputi menciptakan lagu (composing), improvisasi, dan re-creating music; di mana individu yang mengalami masalah diminta untuk memainkan musik dengan tujuan membantu dirinya dan memotivasi agar mempercepat penyembuhan. Jika dikaitkan dengan CBT dalam memandang inattention, selanjutnya dapat disimpulkan bahwa konseling kelompok CBT dengan teknik active music therapy adalah layanan yang diberikan untuk membantu YRD yang menunjukkan inattention, sehingga dapat membantu YRD agar mampu menyadari pikiran-pikiran lain yang menyebabkan inattention, kemudian mengevaluasi pikirannya, dan selanjutnya YRD bereksplorasi alternatif untuk 
memiliki fokus melalui aktivitas musik secara aktif, yaitu menciptakan lagu (composing), improvisasi, dan re-creating music.

\section{Tujuan dan Tahapan Passive vs Active Music Therapy dalam Konseling CBT}

Menurut Wigram et al. (2002), tujuan pelaksanaan konseling CBT dengan teknik passive music therapy adalah untuk membantu individu yang menunjukkan low self-acceptance, menyadari perasaannya tersebut, kemudian mengevaluasi perasaannya tersebut berdasarkan pengalaman masa lalunya yang tidak menyenangkan, selanjutnya ia berdamai dengan pengalaman masa lalunya tersebut, dan mengoptimalkan kemampuan yang dimiliki agar dapat memiliki high self-acceptance, melalui aktivitas mendengarkan musik secara reseptif/pasif dengan guided imagery. Sementara, tujuan pelaksanaan konseling kelompok CBT dengan teknik active music therapy adalah untuk membantu individu yang menunjukkan inattention, sehingga dapat membantunya dalam menyadari pikiran-pikiran lain yang menyebabkan hal tersebut terjadi, kemudian mengevaluasi pikirannya, dan selanjutnya ia bereksplorasi alternatif untuk memiliki focus yang lebih baik, melalui aktivitas musik secara aktif, yaitu menciptakan lagu (composing), improvisasi, dan re-creating music. Adapun perbandingan tujuan dari pelaksanaan konseling kelompok CBT dengan teknik passive dan active music therapy bagi individu visual impairment ialah sebagai berikut:

Tabel 1. Perbandingan Tujuan Konseling CBT dengan Passive vs Active Music Therapy

\section{Passive Music Therapy negatif yang selama ini menyebabkan low self-acceptance. \\ 2. YRD mengenal dan menyadari automatic thought dan distorsi kognitif yang dimiliki melalui aktivitas passive music therapy dengan guided imagery.}

1. YRD mampu menyadari pikiran-pikiran 1. YRD mampu menyadari pikiran-pikiran lain

3. YRD mengevaluasi low self-acceptance yang dimiliki berdasarkan pengalaman masa lalunya yang tidak menyenangkan.

4. YRD berdamai dengan masa lalunya melalui 4. YRD bereksplorasi alternatif untuk mengubah imajinasi positif yang terbimbing (guided imagery).

5. YRD dapat menjadi rileks dan meningkatkan low self-acceptance yang dimiliki.

6. YRD dapat meningkatkan rasa bahagianya, 6 . sehingga lebih dapat optimal dalam hidup kesehariannya.

7. YRD memiliki keterampilan untuk melawan 7. YRD memiliki keterampilan untuk melawan pikiran dan keyakinan maladaptif dengan yang selama ini menyebabkan inattention.

2. YRD mengenal dan menyadari automatic thought dan distorsi kognitif yang dimiliki melalui aktivitas menciptakan lagu (composing), improvisasi, dan re-creating music.

3. YRD mengevaluasi inattention yang dimiliki berdasarkan apa yang ia rasakan saat ini melalui aktivitas menciptakan lagu (composing), improvisasi, dan re-creating music.

pikiran-pikirannya yang lain, melalui penulisan lirik-lirik yang terapeutik.

5. YRD memiliki pikiran yang lebih adaptif, sehingga mampu memiliki fokus yang lebih baik.

6. YRD dapat dapat terus mempertahankan pikiran yang lebih adaptif, sehingga lebih dapat optimal dalam hidup kesehariannya. pikiran-pikiran yang tidak penting dengan 
automatic thought alternative dengan bantuan guided imagery.

8. YRD mampu menyadari kemampuan yang dimilikinya melalui proses bantuan guided imagery.

9. YRD dapat meningkatkan self-acceptance yang dimiliki untuk kehidupannya seharihari, melalui proses bantuan guided imagery.

10.YRD memiliki keterampilan yang efektif dilakukan untuk mengaktivasi perilaku positif dalam kehidupan sehari-hari. automatic thought alternative yang dituliskan ke dalam lirik-lirik lagu yang ia ciptakan sendiri.

8. YRD mampu menyadari kemampuan yang dimilikinya melalui proses menciptakan lagu bersama-sama dengan konselor.

9. YRD dapat meningkatkan attention yang dimiliki, melalui penciptaan lirik-lirik lagu yang mengandung muatan motivasi.

10.YRD mampu membuat komitmen dan harapan-harapan positif melalui lagu yang diciptakan atau mainkan.

11.YRD memiliki keterampilan efektif yang dapat dilakukan untuk mengaktivasi perilaku positif dalam kehidupan sehari-hari.

\section{PENUTUP}

\section{Simpulan}

Program yang dirancang bagi YRD sebagai individu yang memiliki visual impairment ini, disesuaikan dengan permasalahan yang tengah dialami yaitu terkait low self-acceptance dan inattention. Pemberian passive music therapy berbasis cognitive behavior therapy (CBT) akan berfokus pada permasalahan low self-acceptance, yang mana akan dibantu oleh para konselor volunteer atau peer-counselor. Sementara pemberian active music therapy berbasis cognitive behavior therapy (CBT) berfokus pada permasalahan inattention, yang mana dibantu oleh peneliti sendiri sebagai konselor.

Peneliti berharap agar program yang telah disusun, benar-benar dapat diterapkan juga oleh pihak lembaga dan keluarga YRD, agar YRD dapat memiliki self-acceptance yang cukup baik dan dapat meningkatkan attentionnya.

\section{Saran}

Peneliti memberikan saran agar pihak-pihak terkait dapat terus menjalin kerjasama yang baik, yaitu antara lembaga dan keluarga untuk terus memberikan stimulus dan pengajaran/konseling kepada YRD. Selain itu juga, diharapkan lembaga dan keluarga dapat sama-sama berupaya untuk terus melatih YRD agar memiliki self-acceptance dan attention yang cukup baik, sehingga YRD dapat memiliki well-being yang lebih baik lagi dalam menjalankan mobilitasnya sehari-hari. 


\section{DAFTAR PUSTAKA}

Baker, F. A., Gleadhill, L. M., Dingle, G. A. (2007). Music therapy and emotional exploration: Exposing substance abuse clients to the experiences of non-drug-induced emotions. The Arts in Psychotherapy, 34, 321-330. Doi: http://dx.doi.org/10.1016/j.aip.2007.04.005

Bastemur, S., Dursun-Bilgin, M., Yildiz, Y., \& Ucar, S. (2016). Alternative therapies: New approaches in counseling. Procedia-Social and Behavioral Sciences, 217, 1157-1166.

Bradley, L. J., Whiting, P., Hendricks, B., Parr, G., \& Jones Jr, E. G. (2014). The use of expressive techniques in counseling. Journal of Creativity in Mental Health, 3(1), 44-59.

Capuzzi, D., \& Gross, D.R. (2011). Counseling and psychotherapy: Theories and intervention (5th ed.). New Jersey: Merril Prentice Hall.

Corey, G. (2013). Theory and practice of counseling and psychotherapy (9th ed.). California: Brooks/Cole.

Djohan. (2006). Terapi Musik Teori dan Aplikasi.Yogyakarta: Galang Press.

Flowers, P. J., \& Wang, C. H. (2002). Matching verbal description to music excerpt: The use of language by blind and sighted children. Journal of Research in Music Education, 50(3), 202214.

Fredenburg, H. A., Silverman, M. J. (2014). Psychotherapy effects of cognitive-behavioral music therapy on fatigue in patients in a blood and marrow transplantation unit: A mixed-method pilot study. The Arts in Psychotherapy, 41, 433-444. Doi: http://dx.doi.org/10.1016/j.aip.2014.09.002

Giovagnoli, A. R., Oliveri, S., Schifano, L., \& Raglio, A. (2014). Active music therapy improves cognition and behaviour in chronic vascular encephalopathy: A case report. Complementary therapies in medicine, 22(1), 57-62.

Gladding, S.T. (2016). The creative arts in counseling. Alexandria, VA - USA: American Counseling Association.

Gómez Gallego, M., \& Gómez Garcia, J. (2017). Music therapy and Alzheimer's disease: Cognitive, psychological, and behavioural effects. Journal of Neurología. Doi: http://dx.doi.org/10.1016/j.nrl.2015.12.003

Gómez-Romero, M., Jiménez-Palomares, M., Rodríguez-Mansilla, J., Flores-Nieto, A., GarridoArdila, E.M., \& González-López-Arza, M. V. (2016). Benefits of music therapy on behaviour disorders insubjects diagnosed with dementia: A systematicreview. Journal of Neurología. Doi: http://dx.doi.org/10.1016/j.nrl.2014.11.001

Gourgey, C. (1998). Music therapy in the treatment of social isolation in visually impaired children. RE: view, 29(4), 157.

Halgin, P., Richard, \& Whitbourn, K. S. (2003). Abnormal Psychology: International Edition (4 ${ }^{\text {th }}$ ed.). USA: Mc Graw-Hill. 
Hallahan, D. P., \& Kauffman, J. M. (1994). Exceptional Children: Introduction to Special Education. Boston: Allyn and Bacon.

Hallahan, D. P. \& Kauffman, J. M. (2006). Exceptional Children: Introduction to Special Education (International Edition, $10^{\text {th }}$ ed.). Boston: Allyn \& Bacon.

Hui-Chi Li RN, Hsiu-Hung Wang RN, Fan-Hao Chou RN, \& Kuei-Min Chen RN. (2015). The effect of music therapy on cognitive functioning among older adults: A systematic review and meta-analysis. JAMDA The Society for Post-Acute and Long-Term Care Medicine, 16, 71-77. Doi: http://dx.doi.org/10.1016/j.jamda.2014.10.004

Laura, D., Sylvie, J., \& Aurore, S. (2015). The effects of music therapy on anxiety and depression. Ann Depress Anxiety, 2(4), 1057.

Malinovská, O., \& Ludíková, L. (2017). ICT in teaching foreign languages to adult people with acquired severe visual impairment. Procedia-Social and Behavioral Sciences, 237, 311-318.

Malinovska, O., \& Majerova, H. (2015). Typhlotechnics for persons with visual impairment and quality of life. Procedia-Social and Behavioral Sciences, 171, 438-441.

Mangunsong, F. (2009). Psikologi dan pendidikan anak berkebutuhan khusus (jilid kesatu). Depok: LPSP3.

Marylin. F. (2005). Special Education. United State: Pearson Education, Inc.

Mucci, R., \& Mucci, K. (2002). The healing sound of music. Jakarta: PT. Gramedia Pustaka Umum.

Robb, S. L. (2003). Music interventions and group participation skills of preschoolers with visual impairments: Raising questions about music, arousal, and attention. Journal of Music Therapy, $X L$ (4), 266-282.

Rogers, D. R. B., Sue Ei, Rogers, K. R., Cross, C. L. (2007). Evaluation of a multi-component approach to cognitive-behavioral therapy (CBT) using guided visualizations, cranial electrotherapy stimulation, and vibroacoustic sound. Complementary Therapies in Clinical Practice, 13, 95-101. Doi: http://dx.doi.org/10.1016/j.ctcp.2006.10.002

Sharf, R. S. (2012). Theories of psychotherapy and counseling: Concepts and cases (5th ed.). California: Brooks/Cole.

Skudrzyk, B., Zera, D. A., McMahon, G., Schmidt, R., Boyne, J., \& Spannaus, R. L. (2014). Learning to relate: Interweaving creative approaches in group counseling with adolescents. Journal of Creativity in Mental Health, 4(3), 249-261.

Spahn, C. (2015). Treatment and prevention of music performance anxiety. Progress in Brain Research, ISSN 0079-6123. Doi: http://dx.doi.org/10.1016/bs.pbr.2014.11.024

Vargas, M. E. R. (2015). Music as a resource to develop cognition. Procedia - Social and Behavioral Sciences, 174, 2989 - 2994. 
Vianna, M. N., Barbosa, A. P., Carvalhaes, A. S., \& Cunha, A. J. (2011). Music therapy may increase breastfeeding rates among mothers of premature newborns: a randomized controlled trial. Jornal de Pediatria, 87(3), 206-212.

White, S. D., \& Davis, N. L. (2011). Integrating the expressive arts into counseling practice (Theory-based interventions). New York: Springer Publishing Company.

Wigram, T., Pedersen, I.N., \& Bonde, L.O. (2002). A comprehensive guide to music therapy (Theory, clinical practice, research and training). London: Jessica Kingsley Publisher, Ltd.

Zarate, R. (2016). Clinical Improvisation and its effect on anxiety: A multiple single subject design. The Arts in Psychotherapy, 48, 46-53. 